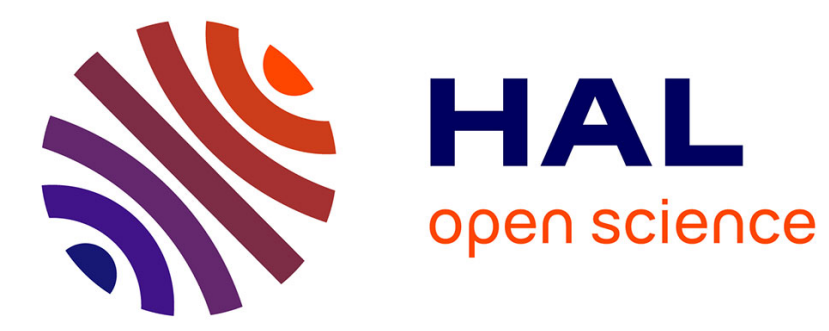

\title{
Towards a novel framework for handling multi-level SLA in cross-organizational enterprise collaboration
}

\author{
Ikbel Guidara, Nawal Guermouche, Tarak Chaari, Saïd Tazi
}

\section{To cite this version:}

Ikbel Guidara, Nawal Guermouche, Tarak Chaari, Saïd Tazi. Towards a novel framework for handling multi-level SLA in cross-organizational enterprise collaboration. Workshop on Factories of the Future (FoF) at I-ESA 2012 Conference, Mar 2012, Valence, Spain. pp.8. hal-00676200

\section{HAL Id: hal-00676200 \\ https://hal.science/hal-00676200}

Submitted on 3 Mar 2012

HAL is a multi-disciplinary open access archive for the deposit and dissemination of scientific research documents, whether they are published or not. The documents may come from teaching and research institutions in France or abroad, or from public or private research centers.
L'archive ouverte pluridisciplinaire HAL, est destinée au dépôt et à la diffusion de documents scientifiques de niveau recherche, publiés ou non, émanant des établissements d'enseignement et de recherche français ou étrangers, des laboratoires publics ou privés. 


\title{
Towards a novel framework for handling multi-level SLA in cross-organizational enterprise collaboration
}

\author{
Ikbel Guidara $^{1,2,3}$ - Nawal Guermouche ${ }^{1,2}$ - Tarak Chaari ${ }^{3}$ \\ - Said Tazi ${ }^{1,2}$ \\ 1 CNRS; LAAS; 7 avenue du colonel Roche, F-31400 Toulouse, France \\ ${ }^{2}$ Univ de Toulouse; INSA; UT1, LAAS; F-31400 Toulouse, France \\ \{iguidara,nguermou,tazi\}@laas.fr \\ ${ }^{3}$ ReDCAD Laboratory, University of Sfax \\ B.P. 1173, 3038 Sfax, Tunisia \\ tarak.chaari@redcad.org
}

ABSTRACT: SLA (Service Level Agreement) is a contract between a service consumer and a service provider. It aims at specifying conditions of services delivery and guarantees to ensure required quality of service (QoS). Nowadays, to satisfy complex client needs, interenterprises collaboration must take place to provide new value added services and form interorganizational extended enterprises. In this context, SLAs composition primitives are needed to define complex dependencies and agreements between services composition. In this paper, we are interested in the problem of SLAs composition where consumer-to-provider and provider-to-provider relationships can hold in cross-organizational enterprise. The aim is to define a framework to assist business decision makers to automatically generate and manage a composition of SLAs to fulfill end-to-end functional and non functional requirements.

KEY WORDS: Service level Agreement (SLA), SLAs composition, collaborative services, SLAs management. 


\section{Introduction}

Nowadays, enterprises are outsourcing their business applications to enable and automate cross-organization collaboration in order to create new value added services. In fact, the rapid globalization of business makes such inter-collaboration very necessary to handle complex business requirements. Opening organizational boundaries aims to promote building, integrating and maintaining large-scale business applications. New mechanisms of exchanges and collaborations to adapt process management to these new organizational models are needed. In this context, SLAs (Service Level Agreement) are becoming an essential tool to govern relationships between different involved partners (Theilmann et al., 10).

Intuitively, an SLA allows defining, in accurate and unambiguous manner, all the features related to requirements and agreements between involved organizations. It clearly spells out rights and obligations of involved parties under a common contract (Lamanna et al., 03). Many efforts have been spent on defining languages (e.g., WSLA (Keller et al., 03)) and tools to handle the life cycle of these SLAs starting from their specifications to their termination passing through their negotiation, validation and execution. These efforts consider simple client-provider patterns involving only the end client and the direct providers that will fulfil his requirements (Haq et al., 11). With the proliferation of service providers and with the growth of complexity of business needs, such patterns are very restrictive. Usually a composition of different service's partners, which can hold collaborative and competitive relationships, is inevitable to satisfy complex business requirements. With such configuration, apart from client-producer SLA pattern, there is a great need to define composite SLAs that can involve collaborative and competitive producer/consumer partners.

In this position paper, we are particularly interested in the problem of building and managing composite SLAs for collaborative-networked enterprises. In this context, it is crucial to define an expressive and rigorous SLA specification to clearly describe the consumer/provider features such as functional and nonfunctional requirements, offers, and priorities. Based on such SLA model, we intend to provide a framework to automatically and dynamically generate and manage multi-party SLAs composition. Generating and managing a composition of SLA in an automatic way is not a trivial task. Indeed, to fulfil such a goal, we need to define a complete chain that allows building complex SLAs, negotiating the incompliant requirements, selecting the most suitable composite SLA and finally validate the multi-party SLAs composition. Since we consider collaborative and competitive relationships, defining a negotiation step is relevant to reach a mutually acceptable agreement.

The remaining of this paper is organized as follows. Section 2 presents the background knowledge and related work. Section 3 introduces an overview of our framework for SLA composition and gives an idea about the different steps of our approach. We conclude this paper in section 4 . 


\section{State of the art}

Several efforts and languages have been proposed in the field of SLA management. In this section we focus on the existing work on the used languages to implement composite SLAs and the proposed frameworks to manage them. In (Keller et al., 03), the authors describe the language WSLA (Web Service Level Agreement) which defines three main components of an SLA: contract parties, service description and obligations (Service Level Objectives (SLOs) and action (guarantees). WS-Agreement (Pichot et al., 08) language allows the specification of the capabilities of service providers and the monitoring of SLA. These two languages don't allow the specification of multiple parties in the SLA. This is not suitable with the requirement of new enterprises collaboration in which multiple parties can collaborate together and share a global SLA.

In (Haq et al., 11) authors are interested in hierarchical SLAs aggregation and don't cater for collaboration capabilities between collaborative/competitive services. In (Blake et al., 07), the authors have highlighted the importance of SLAs composition associated with Web service workflow compositions. Their approach is limited to predefined aspects and measures and it considers only a single-level composition. Another work on SLA has been proposed in (Ludwig et al., 08) allowing dynamic management of SLAs in a service composition. As presented, producer-to-producer patterns are not taken into account. In (Winkler et al., 10), the authors propose an approach to automatically manage composite SLAs. They define a dependency model to validate and evaluate dependencies between SLAs. Despite that this work takes into account dependencies between different services in the composition, it doesn't allow generating SLAs composition. Comuzzi et al, (Comuzzi et al., 09) and Theilmann et al, (Theilmann et al., 10) propose multi-layer SLA management approach. The implemented SLA hierarchy captures dependencies between three layers: business layer, software layer and infrastructure layer. These two works focus on the translation of metrics from business layer to various lower layers and don't consider composite SLAs of multi-partners.

Comparing to existing works, our aim is to provide automatic SLA composition framework to build and manage multi-party SLAs composition in which several relationships can take place. In the next section, we discuss the related features of this framework.

\section{SLA composition approach}

The aim of this ongoing work is to provide a framework to generate the most suitable and efficient SLA composition to govern end-to-end functional and nonfunctional requirements of networked enterprises. To do so, the first important ingredient of such a framework is to define an SLA model to formalize all the related non-functional requirements associated to functional requirements. Based on 
this model, the next step consists in building and providing a global SLA based on composition, negotiation, selection and validation processes. This framework considers several kinds of relationships that can hold between different partners. For instance, in this ongoing work, we are considering an aircraft-building scenario in which multiple aerospace manufacturers must collaborate together to ensure the product provision throughout the production lifecycle (Figure 1). These partners have different roles and maintain different relationships. For example, some partners are affiliated with the main aircraft factory and other partners maintain a subcontracting business relationship. Each partner will provide parts of the product and may require other services from other partners. To fulfil the global aircraftbuilding objectives, it is mandatory to compose the suitable services and to generate the corresponding composite SLA which complies with functional and QoS requirements (Andrikopoulos et al., 10) during the aircraft construction.

In such setting, and as said previously, partners can maintain different relationships such as subcontracting relationships (e.g., Partner 2 and Partner 3 in Figure 1) or collaborative relationships (e.g., Partner 4 and Partner 5 in Figure 1).

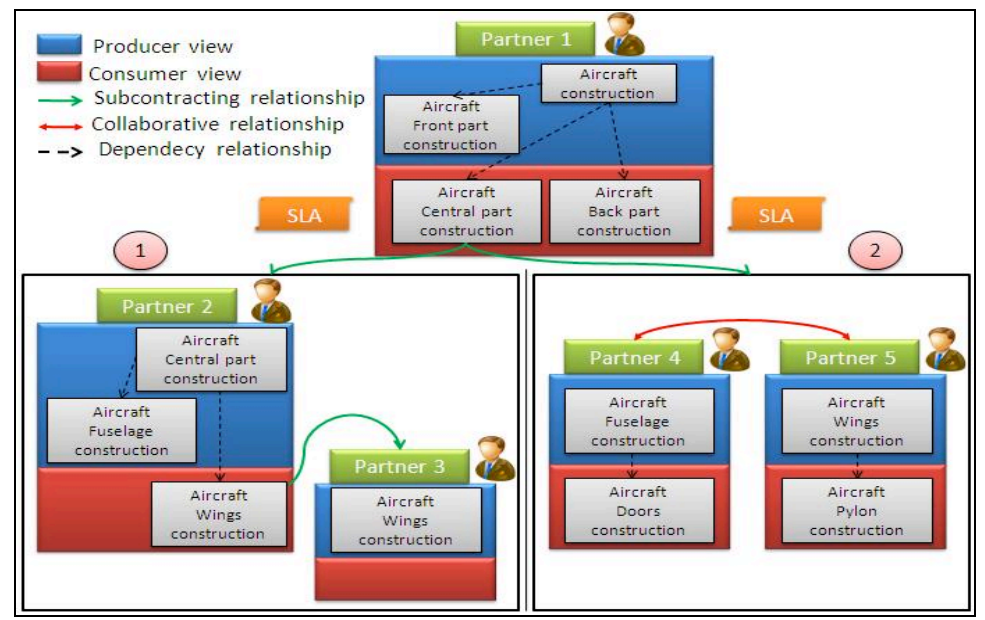

Figure 1. Subcontracting and collaborative relationships

To summarize, our approach is built upon four steps: (1) definition of a rigorous model to specify all the necessary elements of SLA, such as offers, requirements, and priorities of each partner, (2) definition of SLA composition primitives, (3) definition of SLA negotiation process, and (4) selection of the most suitable SLA composition. Hereafter, we present each step.

\subsection{Offers and requirements model of each partner}

In the literature, involved parties in an SLA can play exactly one role: either consumer or producer. Based on this pattern, existing approaches aim at defining 
techniques to govern producer-consumer relationships. This is very restrictive and doesn't consider the case in which each party can play multiple roles. In fact, in inter-organizational enterprises, each party provides multiple services to other parties and consumes services from other parties. To cope with theses configurations, it is mandatory to define a flexible and efficient framework which considers multi-party SLA management where the involved partners can be producer, consumer, competitor, and/or collaborator at the same time. To reach this goal, the first basic step consists in providing a model to specify both requirements and offers of each party associated with important concepts such as those related to priorities and penalties.

As can be seen in Figure 1, in the model we distinguish two view parts: (1) producer view, and (2) consumer view. The producer view specifies what the partner can offer. This view is exposed to consumers and is hidden to producers. The consumer view states requirements that must be satisfied by other partners. It is hidden to customers and exposed to producers. We note that offers of each partner can be assigned to requirements. For instance, in Figure 1, to perform the required service "Aircraft construction", the partner 1 requires the service "Aircraft central part construction" from other partners.

Apart from offers and requirements, it is important to consider the concepts of requirement priority and negotiability. To capture the priority concept, our model relies on weights associated to requirements. A requirement with a highest weight must be satisfied in priority. These weights are required in the selection and the negotiation phases. Regarding the requirement/offer negotiability, it allows to state clearly if the requirement/offer can be negotiable or not.

Based on the model we define, our first goal consists in providing SLA composition process. This step is described below.

\subsection{SLA composition}

As discussed above, to satisfy given consumer requirements, SLA composition is required. With the proliferation of services, several possible SLA compositions can exist. We intend particularly to provide mechanisms to build composite SLA which matches the intended requirements.

Back to the example depicted in Figure 1. For instance, we can see two possible SLA compositions:

- Composition 1: Partner 1, Partner 2 and Partner 3

- Composition 2: Partner 1, Partner 4 and Partner 5

These two compositions are competitive. In fact, two kinds of relations can hold between stakeholders:

- Collaborative relations: which hold between partners offering different complementary services (e.g., partner 4, and partner 5) 
- Competitive relations: which hold between partners offering the same service (e.g., partner 3 and partner 5)

The composition process will provide composite SLAs that correspond to each possible service composition. In case there is no a composition that fully satisfies the given requirements, we aim to provide a multi-criteria approach to select a set of relevant possible SLA compositions, which will be the input of the negotiation process (see Section 3.3). The selection will be performed based on several parameters, such as priorities, arguments, and negotiability.

\subsection{SLAs Negotiation Process}

In SLA composition, it is necessary that end-to-end functional and associated non-functional parameters comply with the consumer expectations. As said previously, we look for the best SLA composition that covers all functional and nonfunctional requirements. If there is no SLA composition that satisfies all the consumer requirements, we adopt a multi-party SLA negotiation process. Automated SLA negotiation aims at resolving disagreements between collaborative parties in order to reach a mutual agreement. Several negotiation strategies can be considered such as the trade-off and the concession strategies (Yan et al., 07. Each party negotiates multiple requirements/offers with different partners giving different arguments (Rahwan et al., 03). Argument is an interesting concept in SLA management, and more particularly, in SLA negotiation step. It allows partners to improve and justify their offers and requirements. The most used argument types in the literature are: appeals, rewards and threats (Monteserin et al., 11). In our work, we propose to define classes of arguments to be used in the negotiation process which can be associated to the requirement's priority. More particularly, we aim to define appropriate arguments generation rules, negotiation techniques, protocols, and strategies.

\subsection{SLAs Selection Process}

The result of the previous step will be a set of negotiated SLA compositions. In this context, it is important to define selection mechanisms to choose the best and the most appropriate SLA composition. To do so, we plan to define functions and metrics to measure the relevance and utility of each composite SLA. This will allow comparing the different SLAs and choosing the appropriate one. The relevance and utility of each composite SLA will be characterized using several parameters to define decision-making mechanisms. Aggregation and logical patterns (Haq et al., 11) can be studied, enhanced, and integrated. 


\section{Conclusion}

Usually, SLA is a bilateral contract between a consumer and a provider. Nowadays in business environments, multiple parties playing different roles must collaborate to fulfill complex requirements. Therefore, defining SLAs between each pair of consumer-provider participating in the collaboration is no longer suitable. In fact, multiple dependencies between producer's offers and requirements can arise. Therefore, we need to define mechanisms to build a multi-party composite SLA. In this paper, we presented the global overview of our ongoing work to handle these compositions in a novel SLA management framework. First, we aim to propose an SLA model to specify all the required features such as functional and non-functional parameters associated to several concepts such as priority and negotiability where partners can maintain different kind of relationships. This model is the input of the composition process whose goal is to build an SLA composition that fulfils every partner requirement. In case there is no an ideal SLA composition, we believe that we must enhance SLA composition lifecycle by a negotiation process. This latter will try to enforce agreements between the different partners. This negotiation should be done with a minimum human interaction due to the proliferation of partner's services and to the dynamic nature of business relationships. The automation of the negotiation process is a challenging problem and requires deeper investigations. In this context, we aim to propose a generic SLA composition and management framework. This framework relies on several phases which consist in modeling, composing, selecting, negotiating, and finally validating the generated multi-party composite SLA. In our ongoing work, we intend to define the corresponding techniques to implement these different phases.

\section{Acknowledgment}

Part of this work has been supported by FP7-ICT IMAGINE research and development project, co-funded by the European Commission under the "Virtual Factories and Enterprises" (FoF-ICT- 2011.7.3, Grant Agreement No: 285132).

\section{References}

ANDRIKOPOULOS V., FUGINI M., PAPAZOGLOU M. P., PARKIN M., PERNICI B., SIADAT S. H., "QoS Contract Formation and Evolution », BUCCAFURRI F., SEMERARO G., Eds., E-Commerce and Web Technologies, 11th International Conference, ECWeb 2010, Bilbao, Spain, September 1-3, 2010. Proceedings, vol. 61 de Lecture Notes in Business Information Processing, Springer, 2010, p. 119-130.

BLAKE M. B., CUMMINGS D. J., "Workflow Composition of Service Level Agreements.», IEEE SCC, IEEE Computer Society, 2007, p. 138-145. 
COMUZZI M., KOTSOKALIS C., RATHFELDER C., THEILMANN W., WINKLER U., ZACCO G., " A Framework for Multi-level SLA Management. », DAN A., GITTLER F., TOUMANI F., Eds., ICSOC/ServiceWave Workshops, vol. 6275 de Lecture Notes in Computer Science, 2009, p. 187-196.

HAQ I. U., HUQQANI A. A., SCHIKUTA E., « Hierarchical aggregation of Service Level Agreements. », Data Knowl. Eng., vol. 70, no 5, 2011, p. 435-447.

KELLER E., LUDWIG H., «The WSLA Framework : Specifying and Monitoring Service Level Agreements for Web Services ", Journal of Network and Systems Management, vol. 11, 2003, page 2003.

LAMANNA D. D., SKENE J., EMMERICH W., "SLAng : A Language for Defining Service Level Agreements. ", FTDCS, IEEE Computer Society, 2003, p. 100-.52 L'objet $-8 / 2002$. LMO'2002

LUDWIG A., FRANCZYK B., " Managing Dynamics of Composite Service Level Agreements with COSMA. », MA J., YIN Y., YU J., ZHOU S., Eds., FSKD (4), IEEE Computer Society, 2008, p. 584-589.

MONTESERIN A., AMANDI A., « Argumentation-based negotiation planning for autonomous agents », Decis. Support Syst., vol. 51, 2011, p. 532-548, Elsevier Science Publishers B. V.

PICHOT A., WÄLDRICH O., ZIEGLER W., WIEDER P., « Towards Dynamic Service Level Agreement Negotiation : An Approach Based on WS-Agreement. », CORDEIRO J., HAMMOUDI S., FILIPE J., Eds., WEBIST (Selected Papers), vol. 18 de Lecture Notes in Business Information Processing, Springer, 2008, p. 107-119.

RAHWAN, RAMCHURN S. D., JENNINGS N. R., MCBURNEY P., PARSONS S., SONENBERG L., " Argumentation-Based Negotiation », The Knowledge Engineering Review, vol. 18, no 3, 2003, p. 343-375.

THEILMANN W., HAPPE J., KOTSOKALIS C., EDMONDS A., KEARNEY K., LAMBEA J., «A Reference Architecture for Multi-Level SLA Management », Journal of Internet Engineering, vol. 4, no 1, 2010.

WINKLER M., SPRINGER T., SCHILL A., «Automating Composite SLA Management Tasks by Exploiting Service Dependency Information. ", BROGI A., PAUTASSO C., PAPADOPOULOS G. A., Eds., ECOWS, IEEE Computer Society, 2010, p. 59-66.

YAN J., KOWALCZYK R., LIN J., CHHETRI M. B., GOH S., ZHANG J. Y., " Autonomous service level agreement negotiation for service composition provision ", Future Generation Comp. Syst., vol. 23, no 6, 2007, p. 748-759. 